\title{
Fever, Splenomegaly, and Pancytopenia: Histoplasma-Associated Hemophagocytic Lymphohistiocytosis
}

\author{
Arjun Gupta, $M D^{7}$, Mrinal Agrawal, $B S^{2}$, and Jesse Jaso, $M D^{3}$ \\ 'Department of Internal Medicine, University of Texas Southwestern Medical Centre, Dallas, TX, USA; ${ }^{2}$ Rutgers New Jersey Medical School, Newark, \\ NJ, USA; ${ }^{3}$ Departments of Pathology, University of Texas Southwestern Medical Centre, Dallas, TX, USA.
}

KEY WORDS: infectious diseases; hematology; clinical images. J Gen Intern Med 32(9):1060-2

DOI: $10.1007 /$ s11606-017-4029-7

(C) Society of General Internal Medicine 2017

\section{CASE}

A 26-year-old man with acquired immunodeficiency syndrome (AIDS) taking no medications presented with fever and anorexia. Examination showed a febrile cachectic man with splenomegaly. Laboratory analysis revealed pancytopenia (white cell count $2.1 \times 10^{3} / \mu \mathrm{L}$, hemoglobin $8.1 \mathrm{gm} / \mathrm{dL}$, platelet count $49 \times 10^{3} / \mu \mathrm{L}$ ) and CD4 count $2 / \mu \mathrm{L}$. Serum ferritin $(8312 \mathrm{mcg} / \mathrm{L})$ and fasting triglycerides $(312 \mathrm{mg} / \mathrm{dL})$ were elevated. Urinary Histoplasma antigen was positive. Bone marrow biopsy demonstrated histiocytes with intracellular yeast and ingested red blood cells (Figs. 1 and 2). The patient was diagnosed with disseminated histoplasmosis that manifested as hemophagocytic lymphohistiocytosis (HLH) and was treated with antiretroviral therapy, intravenous amphotericin B for 2 weeks, and oral itraconazole for 1 year.

HLH is a hyperinflammatory disorder caused by uncontrolled proliferation of activated lymphocytes and macrophages secreting inflammatory cytokines. ${ }^{1}$ Although a primary genetic form exists, secondary HLH is often associated with immunodeficiency, malignancy, and infection, commonly in patients with AIDS with histoplasmosis. ${ }^{2,3}$ Current diagnostic criteria require fulfillment of five out of eight criteria: fever, splenomegaly, cytopenia, hyperferritinemia, hypertriglyceridemia/hypofibrinogenemia, pathological evidence of hemophagocytosis, low natural killer cell activity, and elevated levels of soluble CD25. ${ }^{1,2}$ Treatment of HLH involves treating the underlying cause; additional therapy with corticosteroids, intravenous immunoglobulin (IVIG), etoposide, or cyclosporine may be required. ${ }^{1}$ 


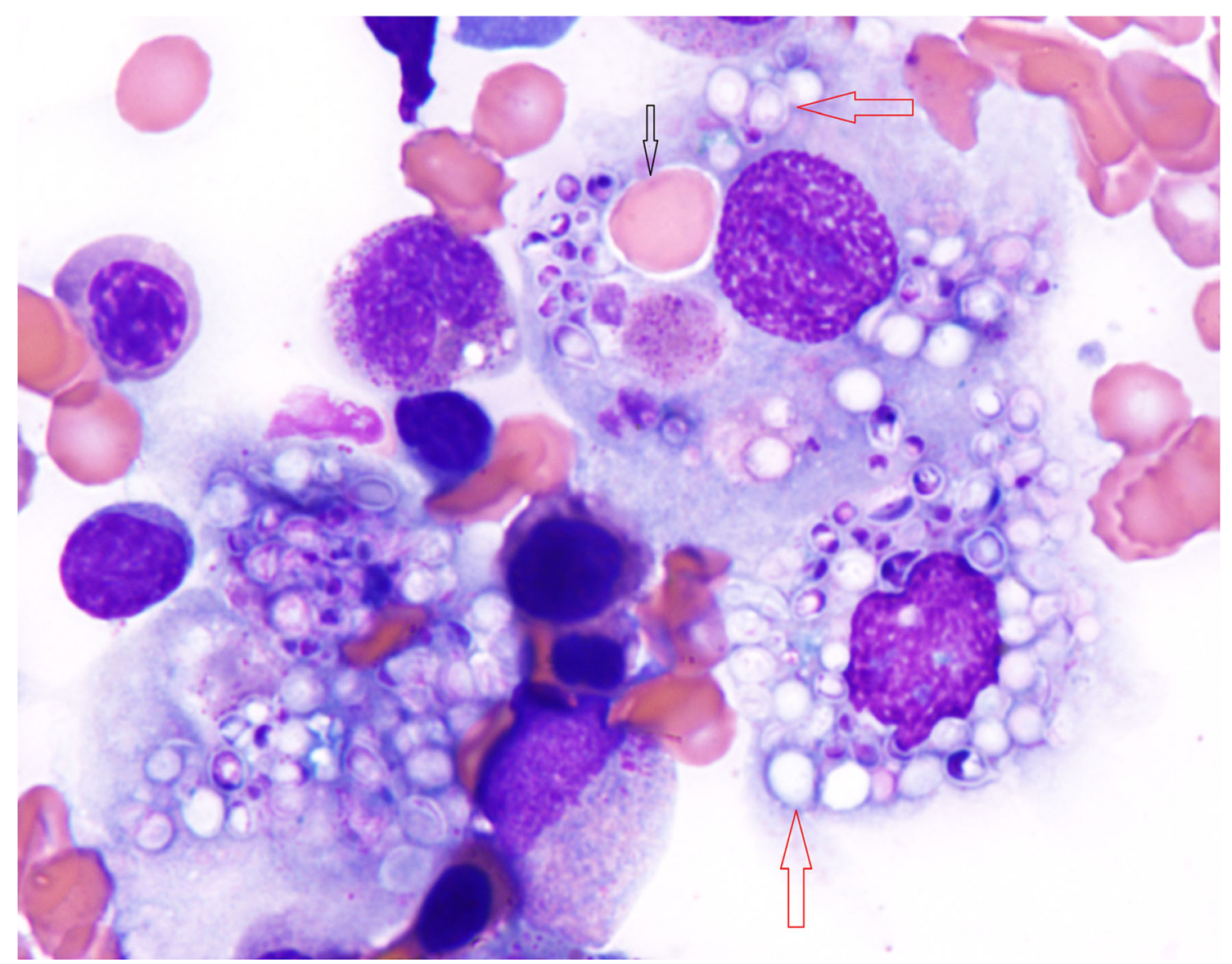

Figure 1 Several enlarged histiocytes containing numerous yeast forms which are surrounded by a clear zone, characteristic of $H i s t o p l a s m a$ (red arrows). One histiocyte (at the top) also contains an engulfed red blood cell (black arrow). Bone marrow, Wright-Giemsa stain, $\times 1000$.

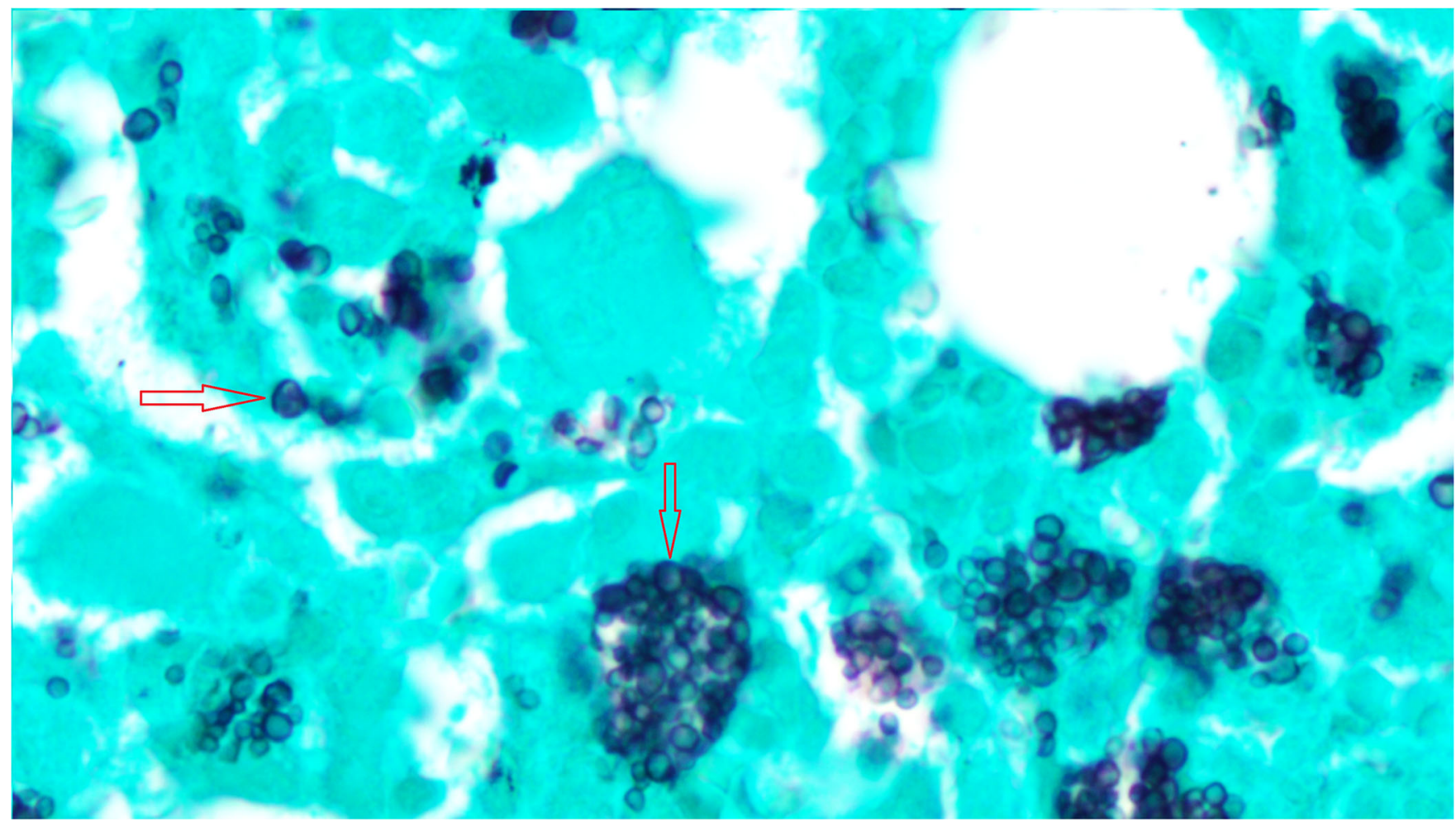

Figure 2 GMS stain highlights numerous fungal organisms identified as capsulated yeast (red arrows). Bone marrow, Gomori methenamine silver (GMS) stain, $\times \mathbf{5 0}$. 
Acknowledgements: There are no funding sources, internal or external.

Corresponding Author: Arjun Gupta, MD; Department of Internal MedicineUniversity of Texas Southwestern Medical Centre, 5323 Harry Hines Blvd, Dallas, TX 75390-9047, USA (e-mail: guptaarjun90@gmail.com).

\section{Compliance with Ethical Standards:}

Conflict of Interest: The authors declare that they do not have a conflict of interest.

\section{REFERENCES}

1. Schram AM, Berliner N. How I treat hemophagocytic lymphohistiocytosis in the adult patient. Blood. 2015;125(19):2908-2914.

2. Huang AM. Hemophagocytic lymphohistiocytosis and disseminated histoplasmosis. Blood. 2014;123(16):2449.

3. Townsend JL, Shanbhag S, Hancock J, Bowman K, Nijhawan AE. Histoplasmosis-induced hemophagocytic syndrome: a case series and review of the literature. Open Forum Infect Dis. 2015;2(2):ofv055. 